\title{
A novel human skin chamber model to study wound infection ex vivo
}

\author{
Lars Steinstraesser - M. Sorkin · A. D. Niederbichler • \\ M. Becerikli $\cdot$ J. Stupka $\cdot$ A. Daigeler $\cdot$ M. R. Kesting • \\ I. Stricker $\cdot$ F. Jacobsen $\cdot$ M. Schulte
}

Received: 2 October 2009 / Revised: 11 November 2009 / Accepted: 16 November 2009 / Published online: 3 December 2009

(c) The Author(s) 2009. This article is published with open access at Springerlink.com

\begin{abstract}
Wound infections with multi-drug resistant bacteria increase morbidity and mortality and have considerable socioeconomic impact. They can lead to impaired wound healing, resulting in rising treatment costs. The aim of this study was to investigate an ex vivo human wound infection model. Human full-thickness skin from the operating room (OR) was placed into the Bo-Drum ${ }^{\circledR}$ and cultivated for 7 days in an air-liquid interphase. On day 8, the skin was inoculated with either (1) Pseudomonas aeruginosa, (2) Staphylococcus aureus ( $\left.10^{5} \mathrm{CFU}, n=3\right)$ or (3) carrier control. 1, 3 and 7 days after inoculation colony forming units in the tissue/media were determined and cytokine expression was quantified. A reliable and reproducible wound infection could be established for 7 days. At this timepoint, $1.8 \times 10^{8} \mathrm{CFU} / \mathrm{g}$ tissue of $P$. aeruginosa
\end{abstract}

\section{Stricker}

Department of Pathology, Ruhr University School of Medicine,

Bochum, Germany

L. Steinstraesser $(\bowtie) \cdot$ M. Sorkin $\cdot$ M. Becerikli $\cdot$ J. Stupka

A. Daigeler $\cdot$ F. Jacobsen $\cdot$ M. Schulte

Department of Plastic Surgery,

BG University Hospital Bergmannsheil,

Ruhr University Bochum, Bochum, Germany

e-mail: lars.steinstraesser@ruhr-uni-bochum.de

\section{A. D. Niederbichler}

Department of Plastic, Hand and Reconstructive Surgery,

Burn Center, Medizinische Hochschule Hannover,

Hannover, Germany

\section{R. Kesting}

Department of Oral and Maxillofacial Surgery,

Klinikum Rechts der Isar,

Technische Universität München, Munich, Germany and $2 \times 10^{7} \mathrm{CFU} / \mathrm{g}$ tissue of $S$. aureus were detected. Immunohistochemical analysis demonstrated bacterial infection and epidermolysis in infected skin. RT-PCR analysis exhibited a significant induction of proinflammatory cytokines after infection. The BO-drum ${ }^{\circledR}$ is a robust, easyto-use, sterilizable and reusable ex vivo full-skin culture system. For investigation of wound infection, treatment and healing, the BO-drum ${ }^{\circledR}$ presents a convenient model and may help to standardize wound research.

Keywords Ex vivo $\cdot$ Infection $\cdot$ Human $\cdot$ Skin . Staphylococcus aureus $\cdot$ Pseudomonas aeruginosa

\section{Introduction}

The increasing incidence of wound infections with multidrug-resistant microbes, such as Staphylococci, Enterococci, and Pseudomonas on intensive care units leads to further increasing morbidity and mortality among these patients and is of considerable socioeconomic impact $[30,31]$.

Further research into the cellular and molecular functions of the skin may lead to improvements in our understanding and management of wounds, but transitional research from the laboratory to the clinic is not always straightforward. Different therapies that affect wound repair have been proposed over the last few decades. To gain deeper insights into the biology and pathophysiology of wound infection, as well as to develop new interventional therapies, it is paramount to employ convenient, easy-touse, and robust experimental models that are versatile and allow translatability. Studies investigating skin disorders in humans are limited owing to ethical concerns, leading to dependence on in vitro and experimental animal models to 
investigate novel therapies and biologic and pathophysiologic pathways [3]. Many models have been developed [7], but in vitro and in vivo models may show poor consistency with clinical situations [27].

In most cases, the wound-models being investigated are artificial since they are inflicted in healthy animals. However, most animals exhibit cell biology, histology, immunology, and biochemistry distinct from humans, with different healing processes, unique complications, and nonequivalent tissue structures (e.g., the contraction of the subcutaneous muscle panniculus carnosus, which is absent in humans, and not by reepithelialization). In addition, animal behavior, therapeutic needs, and skin healing responses (e.g., inflammation, healing mechanisms, and kinetics) also differ from those of humans. The use of animal models to study wound healing under various stimuli and applied therapeutic methods is often an attempt to most expediently duplicate conditions closest to the human patient. Interspecies differences in anatomy and physiology, differences in cause and course between natural human disease and artificially induced nonhuman pathology, and stress experienced by animals in laboratories invariably alter research results. Few in vitro or nonmammalian surrogate experiments accurately or adequately duplicate, or recapitulate, the full physiology of the human model for wound healing purposes [27]. Many research efforts seek new innovative approaches to in vitro modeling of in vivo complexity without clear progress or improved relevance.

In vitro human models help to investigate skin physiology and wound healing in a more equivalent fashion. The major advantage of in vitro models is the opportunity to analyze environmental changes, substrate and doseresponse interactions, and cutaneous immune responses in a standard fashion [7, 13].

Wound closure is usually simulated in vitro by simply creating defects in cell monolayers, and the repopulation of the defect by adjacent cells through the combined action of migration and proliferation is then monitored [1]. However, these models do not reflect the complex process of wound infection and healing because cell cultures of primary cells or cell lines neither have a three-dimensional structure nor show any immune response and systemic interaction. These systems lack the multidimensional aspects to evaluate wound healing. As three-dimensional systems are more representative of normal wound physiology than twodimensional systems [9], several approaches to employ three-dimensional cell cultures have been reported, including prefabricated co-culture systems, three-dimensional gels with incorporated fibroblasts, and keratinocytes cultured on the apical side of the gel $[12,25]$. However, cells cultured in three-dimensional matrices typically composed of type I collagen or fibrin significantly alter their phenotype [6]. Extensive phenotypic changes of contractile fibro- blasts cultured in three-dimensional matrices are observed owing to altered mechanical tensions within the systems. Moreover, newer three-dimensional models utilizing artificially constructed skin equivalents, which are considered by many experts to be phenotypically and histologically similar to that of the in vivo human epidermis [2, 4, 22], are labor and cost intensive or require expert skills to employ these systems.

In contrast to skin equivalents, all cellular elements and their interactions are included in human full-skin culture explants. Therefore, this approach offers improved translation between the investigative laboratory and the clinical setting. Skin infection and wound healing studies in skin explants have been performed previously [16, 27], and in most cases, epithelialization was analyzed [26]. In addition, the change in tensile strength can be monitored in the experimental setting [8]. Standardized burn wounds may also be inflicted in skin explants and assessed for epithelialization by histomorphometry [5]. As a result, this model provides the opportunity to carry out morphologic studies of the connective tissue in wound infection and wound healing [10].

As it is possible to generate wounds and wound infections in skin explants, it is also possible to pursue their potential treatment under in vitro conditions. To discriminate between topical, intradermal, or subdermal treatment, the used model should have discrete superior and inferior compartments, which are strictly separated by the cultured tissue. Therefore, skin explants should be cultured at the air-liquid interface, which induces physiologic maturation of keratinocytes to cornified cells and ensures the preservation of skin barrier function $[19,21]$.

The aim of this study was to develop an effective surrogate chamber model for the ex vivo investigation of the human skin infection and to confirm this model's feasibility for investigation of human skin biology and pathophysiology and novel therapeutic approaches, dermal wounding and infection.

\section{Results}

Infection of human full thickness skin with $P$. aeruginosa and $S$. aureus

To confirm the feasibility of the Bo-Drum ${ }^{\circledR}$ for studies of wound infection and skin physiology the establishment of a wound infection was monitored (Fig. 1). Three days after infection with $S$. aureus and $P$. aeruginosa, tissue samples were harvested and subjected to bacterial count analysis. $S$. aureus infected skin possessed a concentration of $2 \times 10^{7}$ colony forming units $(\mathrm{CFU}) / \mathrm{g}$ tissue $(P=0.09)$. This group of non-invasive bacteria showed only a 


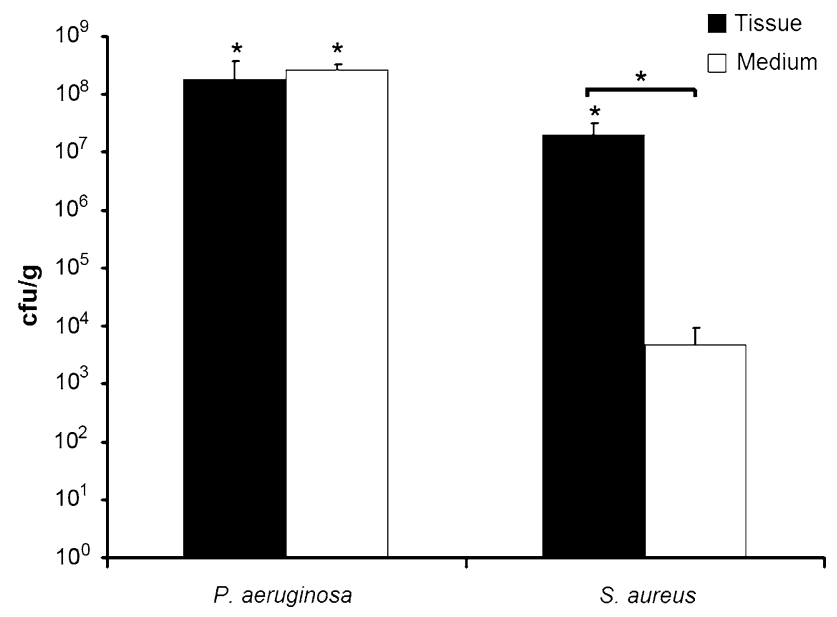

Fig. 1 Bacterial infections. Skin specimens were pre-cultured in Bo-Drums ${ }^{\circledR}$ for 3 days and a dermal wound was created. 3 days after inoculation with $10^{5} \mathrm{CFU} P$. aeruginosa or $S$. aureus, tissue samples were harvested and homogenized. Both, medium and homoginates, were plated on isolation agar to determine CFU counts. Values are displayed as mean \pm SEM

marginal contamination of the medium in a single chamber $\left(4.79 \times 10^{3} \mathrm{CFU} / \mathrm{ml}\right.$ medium $)$. In $P$. aeruginosa infected skin samples, a concentration of $1.84 \times 10^{8} \mathrm{CFU} /$ $\mathrm{g}$ tissue $(P=0.28)$ was determined. Interestingly, this group of invasive bacteria possessed a high concentration of bacteria in the medium $\left(2.6 \times 10^{8} \mathrm{CFU} / \mathrm{ml}\right.$ medium; $P=0.003)$. No bacterial colonialization was observed in carrier controls.

Time course of bacterial counts after infection with $S$. aureus

For investigation of bacterial colonialization in the BoDrum $^{\circledR}$, a time course of bacterial infection has been recorded (Fig. 2). Therefore, the skin was infected with $S$. aureus and incubated for at least 7 days. A significant infection of the skin was seen on day $1\left(6.7 \times 10^{7} \mathrm{CFU}\right.$, $P=0.04)$, increasing up to day $7\left(1.78 \times 10^{9} \mathrm{CFU}\right.$; $P=0.018)$ after inoculation with $S$. aureus, whereas noninfected skin samples did not show any bacterial presence. A significant augmentation of infection was detected on day 3 compared to day $1(P=0.028)$ and on day 7 compared to day $1(P=0.047)$.

Inflammatory response after infection

with S. aureus and P. aeruginosa

For investigation of ex vivo skin inflammatory response after bacterial challenge, cytokine profiling has been performed 3 days after bacterial infection. There was a significant induction of type-I-interferons up to 18 -fold (IFN- $\alpha$;

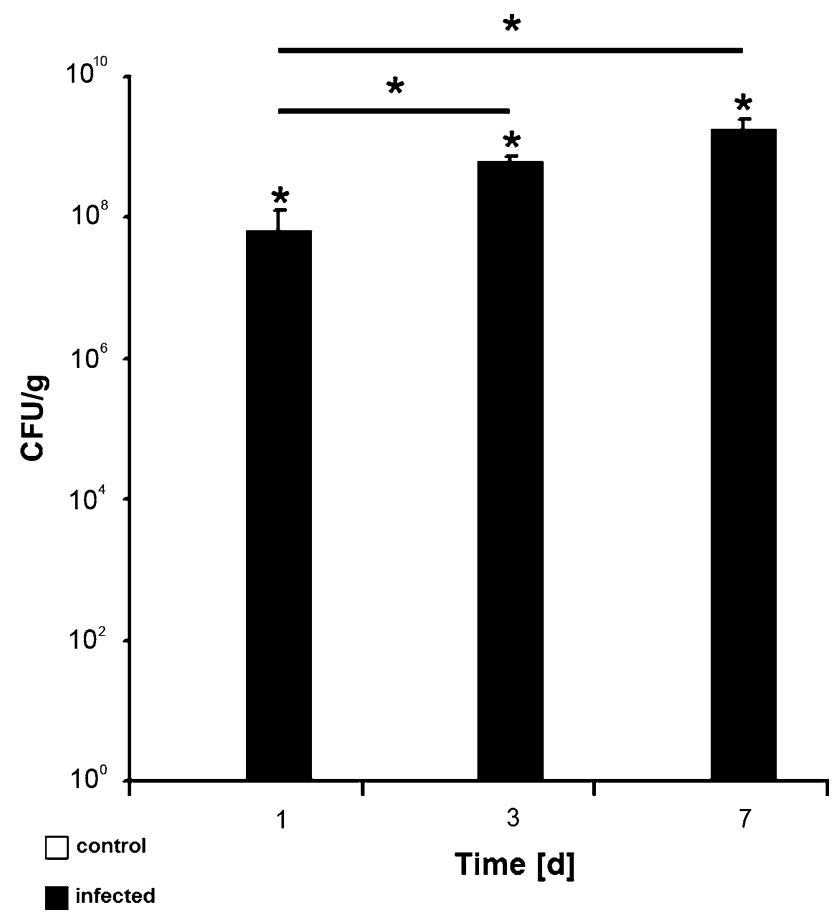

Fig. 2 Time course analysis of bacterial infection. Skin explants were pre-cultured in Bo-Drums ${ }^{\circledR}$ for 3 days. A dermal wound was created and inoculated with $10^{5} \mathrm{CFU}$ S. aureus. After 1, 3 and 7 days, tissue samples were harvested and homogenized. Homoginates were plated on isolation agar to determine CFU counts. Values are displayed as mean \pm SEM

$P$. aeruginosa group; $P=0.0003$ ) after infection with both $S$. aureus and $P$. aeruginosa (Fig. 3). Inflammatory cytokines, such as IL- $1 \alpha$ and IL- 6 showed only a low induction (IL-1 $\alpha$ : 3.3-fold, $P=0.15$; IL-6: 3.26 -fold, $P=0.17$ ) in $S$. aureus infected skin. Interestingly, the $P$. aeruginosa treated group did not show any induction of these cytokines (IL-1 $\alpha$ : 0.5 -fold, $P=0.29$; IL-6: 0.97 -fold, $P=0.97$ ). In contrast, Il-8 and TNF- $\alpha$ exhibited a significant induction ( $P$. aeruginosa, IL-8: 2.6-fold, $P=0.16$; TNF- $\alpha$ : 24 -fold $P=0.001)$.

Time course of cytokine expression after infection with S. aureus

After analysis of $S$. aureus and $P$. aeruginosa induced inflammatory response, it was interesting to see a time dependance in cytokine induction. Therefore, a time course of cytokine expression after inoculation of the skin was determined via qRT-PCR. There was a significant induction of IL-1, increasing up to 48 -fold $\left(P=7 \times 10^{-5}\right)$ compared to non-infected skin samples on day 7 (Fig. 4).

Moreover, a significant induction of IL-6, IL-8 and TNF$\alpha$ has been recorded peaking on day $3[19.3$-fold, $P=0.03$ 


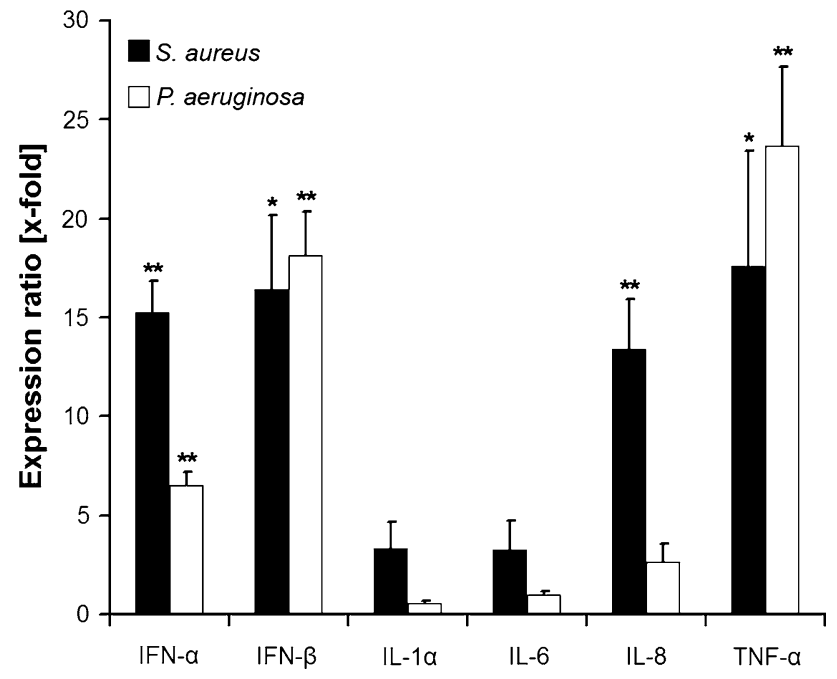

Fig. 3 Proinflammatory response after bacterial challenge. Tissue samples were harvested 3 days after infection with $S$. aureus and $P$. aeruginosa and snap frozen until further use. After homogenization, RNA isolation and cDNA synthesis the expression profiles of selected cytokines were determined using real-time qRT-PCR. Both groups were normalized to the non-infected control group. Values are displayed as mean $\pm \operatorname{SEM}(* P<0.05 ; * * P<0.005)$
(IL-1 $\alpha$ ); 21.5-fold, $P=0.01$ (IL-6); 29.5-fold, $P=0.07$ (IL-8); 6.2-fold, $P=0.002$ (TNF- $\alpha)$ ]. Besides cytokine expression, type-I-interferons (IFN- $\alpha / \beta)$ were also induced after bacterial challenge; peaking on day 3 with a 22.4 -fold (IFN- $\alpha$; $P=0.05$ ) and 7.9-fold (IFN- $\beta ; P=0.008$ ) induction.

Immunohistochemical stainings

To visualize and localize the infection on the skin sections, a haematoxylin/eosin (H\&E) staining has been performed 7 days after $S$. aureus infection (Fig. 5). Inoculated tissue presents with epidermolysis and bacterial infection in comparison to a regularly structured epidermis in the control. An immunohistochemical staining of infected skin with anti-S. aureus antibody (green) and DAPI counterstaining (nuclei; blue) depicts bacterial infection underneath the epidermal layer and underlying dermis. In comparison to non-infected control (right) only few viable cells (blue) are detected at the site of infection, whereas in the control a regular cell distribution can be observed.
Fig. 4 Time course analysis of skin inflammatory response. Tissue samples were harvested 1-7 days after infection and snap frozen until further use. After homogenization, RNA isolation and cDNA synthesis the expression profiles of selected cytokines were determined using real-time qRT-PCR. Both groups were normalized to the non-infected control group. Values are displayed as mean \pm SEM $(* P<0.05)$
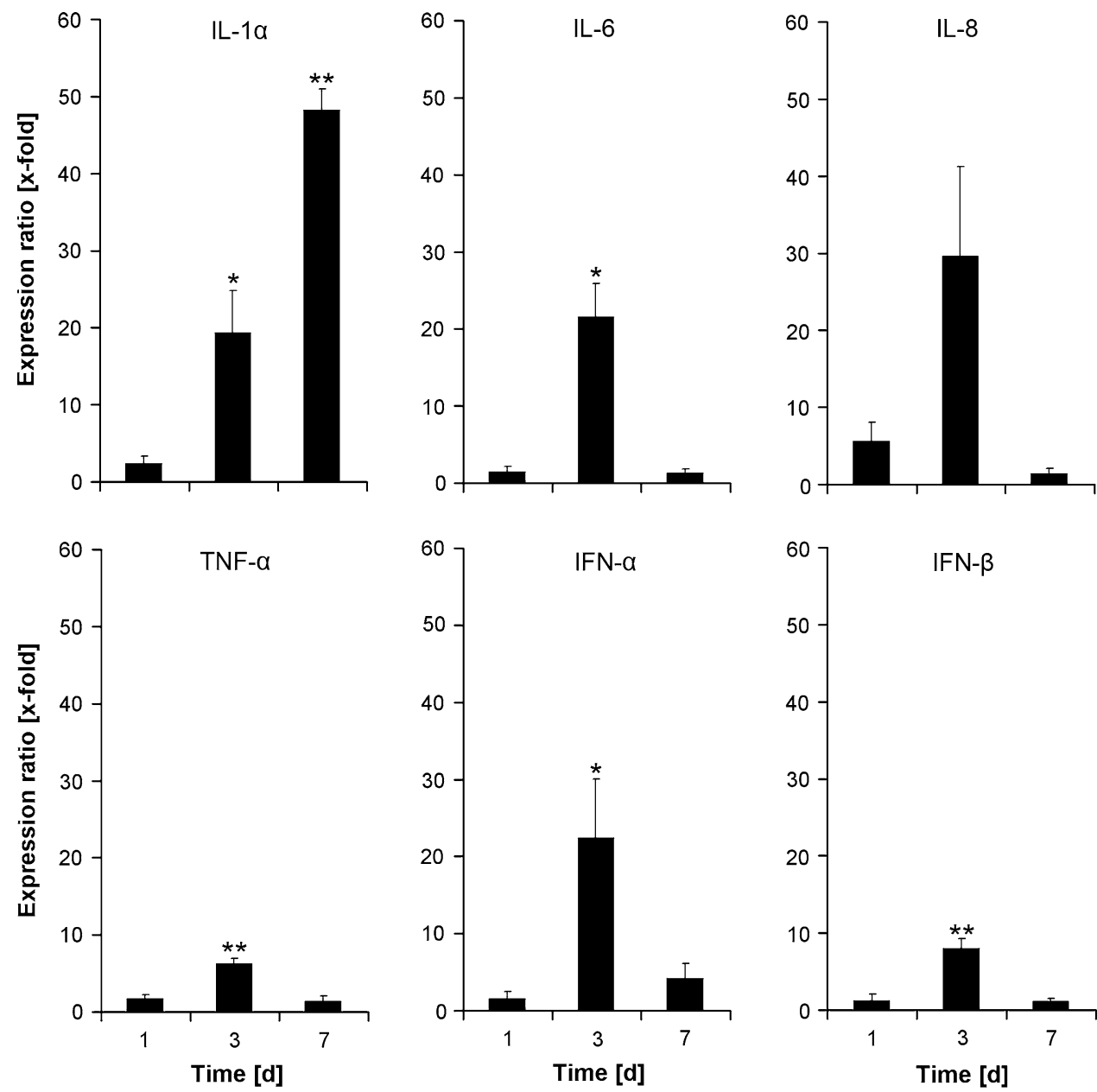
Fig. 5 Histological analysis. $\mathrm{H} \& \mathrm{E}$ staining of infected skin (a) and non-infected control (b) at day 7 after $S$. aureus infection. Inoculated tissue presents with epidermolysis and bacterial infection in comparison to a regularly structured epidermis in the control. Lower panel immunohistochemical staining of infected (c) and non-infected (d) skin with anti-S. aureus antibody (green) and DAPI counterstaining (nucleus, blue)
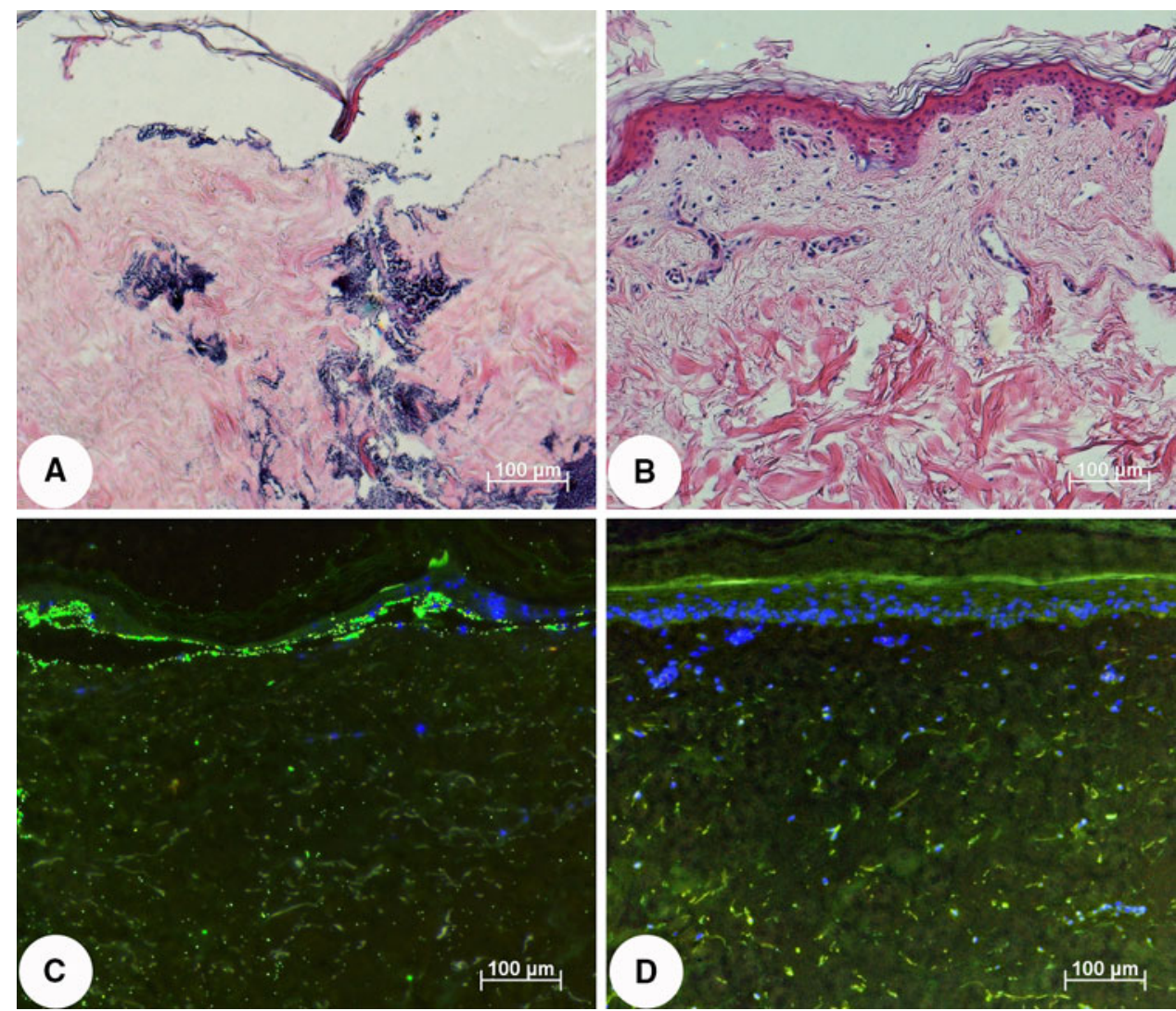

\section{Discussion}

The organ culture may be the only technique to investigate the complexity of skin tissue physiology ex vivo and may therefore bridge the gap between the investigative laboratory and the clinical settings.

In general, there is a lack of the ability to recruit inflammatory cells in organ skin culture models, but in 1998, Moll et al. [17] foresaw that the organ skin culture model could investigate wound healing processes because complex biologic aspects could be observed without any systemic influence. Reliable and robust models are needed to bear the potential of an entire physiologic epithelial environment. In many prior skin organ culture models, explants were sliced into small pieces to prevent excessive dermal contraction and cultured without any tension [14, 17, 29]. This approach minimized potential opportunities and made interventional studies impossible because the pieces under investigation were too small to allow compartmentalization.

Several models using reconstituted skin equivalents were described in previous publications $[2,4,22]$. The major disadvantages of the application of artificially reconstructed skin are the enormous costs in the construction of such skin equivalents. Moreover, an application of native human skin for investigative experiments may be closer to any individual settings than artificially constituted skin equivalents. This study has established a human ex vivo full-skin infection model that allows work with the human skin under defined in vitro conditions. A stainless steel chamber was used to apply tension to the cultured full skin to prevent dermal contraction due to the retraction forces of the elastic fibers and physiologically support skin tissue at an air-liquid interface.

Steinstraesser et al. demonstrated the feasibility of longtime full-skin cultivation. Using this model, an intact epidermal structure with proliferating cells was depicted after a cultivation for approximately 4 weeks [28].

In this study, defined wounds were inflicted into the cultured skin explants. Skin wounds have been infected with two different bacterial strains ( $P$. aeruginosa and $S$. aureus). Since wound infections are defined as a bacterial load of $10^{5} \mathrm{CFU} / \mathrm{g}$ tissue [23], this study demonstrates the feasibility for investigation of dermal infections in the BoDrum $^{\circledR}$. Due to the recess of the inner central opening of the Bo-Drum ${ }^{\circledR}$ a diffusion of non-invasive bacteria into the nutrient could be prevented.

However, this could not prevent a contamination of the medium with $P$. aeruginosa. This can be explained by the invasive behaviour of this bacterial strain.

We further investigated the inflammatory response after bacterial challenge to determine the immunologic function- 
ality of the cultured skin. Since the inflammatory response of the ex vivo skin is comparable to recent studies on skin infection and cutaneous cytokine induction, the feasibility for interventional studies of wound infections using the BoDrum ${ }^{\circledR}$ was confirmed by the data of cytokine induction after wound infection [15, 24]. An inflammatory cytokine gene expression could be monitored in the Bo-Drum ${ }^{\circledR}$ for at least 1 week, suggesting the viability of this model to analyse effects of wound infections on transcriptional level.

In addition, histochemical analysis of the infected skin was performed to visualize the structural settings of infected ex vivo skin. H\&E staining exhibited an intact epidermis in non-infected skin. Consistent to Puissant [20], there was a high bacterial load detected beneath the epidermis in infected samples, leading to an epidermolysis in infected skin samples.

Thus, this model may be used for wound healing studies focussing on the analysis of wound infection. Keratinocytes undergo several kinds of behavioral changes, including proliferation, migration, and differentiation [18], during reepithelialization. However, further studies are clearly needed to demonstrate whether this model is convenient for wound healing studies.

In conclusion, the model described provides two compartments that could be treated or analyzed separately for more than 4 weeks [28]. Wound infection studies can be performed for more than 7 days on mRNA level. The chamber presents a convenient, easy-to-use, and robust model in which ex vivo full-thickness organ culture experiments may be performed. In addition, this model might also provide the opportunity to reduce or finally substitute in vivo animal trials for wound infection and regeneration studies. Moreover, this model provides potential for analysis of potential new therapeutical strategies, topically applied agents as well as gene therapy applications without any systemic influences. Therefore, continuative studies have to be accomplished to investigate its feasibility for other studies of skin physiology and wound treatment, wound healing and wound regeneration.

\section{Materials and methods}

\section{Bo-Drum $^{\circledR}$}

BO-Drum ${ }^{\circledR}$ is constructed out of two disk-shaped, stainless steel plates (base plate and cover plate). The base plate has a diameter of $3 \mathrm{~cm}$ with a central inner opening of $1 \mathrm{~cm}$ and tri-spoke formed gaps to prevent formation of air bubbles during incubation in nutrient media (Fig. 6). The cover plate has a diameter of $3 \mathrm{~cm}$ and a $4 \mathrm{~mm}$ inner central opening that is recessed $3.5 \mathrm{~mm}$ inferior to the remainder of the drum surface. The skin is triangulated into the base plate and the cover plate is secured without rotation force ensuring minimal trauma to the skin during preparation.

Tissue

Skin explants were obtained from adult healthy patients (age range $=19-52$ years) undergoing abdominoplasty surgery. The study was approved by the local ethics committee, and all of the patients gave written informed consent. Immediately postexcision, the skin was washed in antiseptic (Octenisept, Schuelke-Mayr, Norderstedt, Germany) three times for $10 \mathrm{~s}$.

Organ culture

Human skin tissue was washed several times in phosphate buffered saline (PBS) and subcutaneous fat was excised. Next, the tissue was sliced into triangular pieces of $3 \times 3 \mathrm{~cm}$. These pieces were transferred to the base of a stainless steel chamber, placing the epithelial side upward. The upper part of the chamber was bolt down until the tissue was fixed, and during fixation, the skin explants were stretched to prevent contraction. Samples were cultured at the air-liquid interphase using a six-well plate filled with $5.5 \mathrm{ml}$ of culture medium; DMEM (Gibco, 21969-035, Paisley, England), containing 10\% FBS (Hyclone, Logan, Utah), $1 \%$ penicillin/streptomycin, and amphotericin B ( $25 \mu \mathrm{g} / \mathrm{mL}$, PAA, Pasching, Austria) for 3 days. On day 3, culture medium was changed to DMEM (Gibco, 21969035, Paisley, England), containing 10\% FBS (Hyclone, Logan, Utah) and cultured for another 3 days at $37^{\circ} \mathrm{C}$ in a humidified atmosphere containing $5 \% \mathrm{CO}_{2}$.

\section{Bacteria}

For bacterial inoculation, $S$. aureus and $P$. aeruginosa were used. Bacteria were inoculated into Luria-Bertani broth (International Diagnostics Group, Bury, Lancashire, UK) and incubated overnight at $37^{\circ} \mathrm{C}$. The cultures were centrifuged, and the bacterial pellets were diluted to a concentration of $1 \times 10^{8} \mathrm{CFU} / \mathrm{ml}$ by use of the equation $\mathrm{CFU} /$ $\mathrm{ml}=\mathrm{OD}_{600} \mathrm{~nm} \times 2.5 \times 10^{8}$. Each chamber was inoculated with $20 \mu \mathrm{l}$ of bacterial suspension or Dulbecco's phosphate-buffered saline (PAA Laboratories, Linz, Austria) as carrier control.

\section{Epidermal wounding and infection}

For epidermal wounding, the epidermis was scratched using a $3 \mathrm{~mm}$ punching knife. The punch knife was inserted vertically into the Bo-Drum ${ }^{\circledR}$ and the skin was scratched with a minimum force. For wound infection, skin was inoculated with $10^{5} \mathrm{CFU}$ of $P$. aeruginosa (ATCC 27853) 
Fig. 6 Skin culture model. Upper panel depicts structure and alignment of the Bo-Drum ${ }^{\circledR}$. The Bo-Drum ${ }^{\circledR}$ has a 4 mm inner central opening that is recessed $3.5 \mathrm{~mm}$ inferior to the remainder of the drum surface (lid). The skin is triangulated into the base plate and the lid is secured without rotation force ensuring minimal trauma to the skin during preparation. The skin is fixated under tension. Lower panel shows an assembled Bo-Drum ${ }^{\circledR}$, which is further cultured in an air-liquid interface in a six-well plate using standard DMEM medium
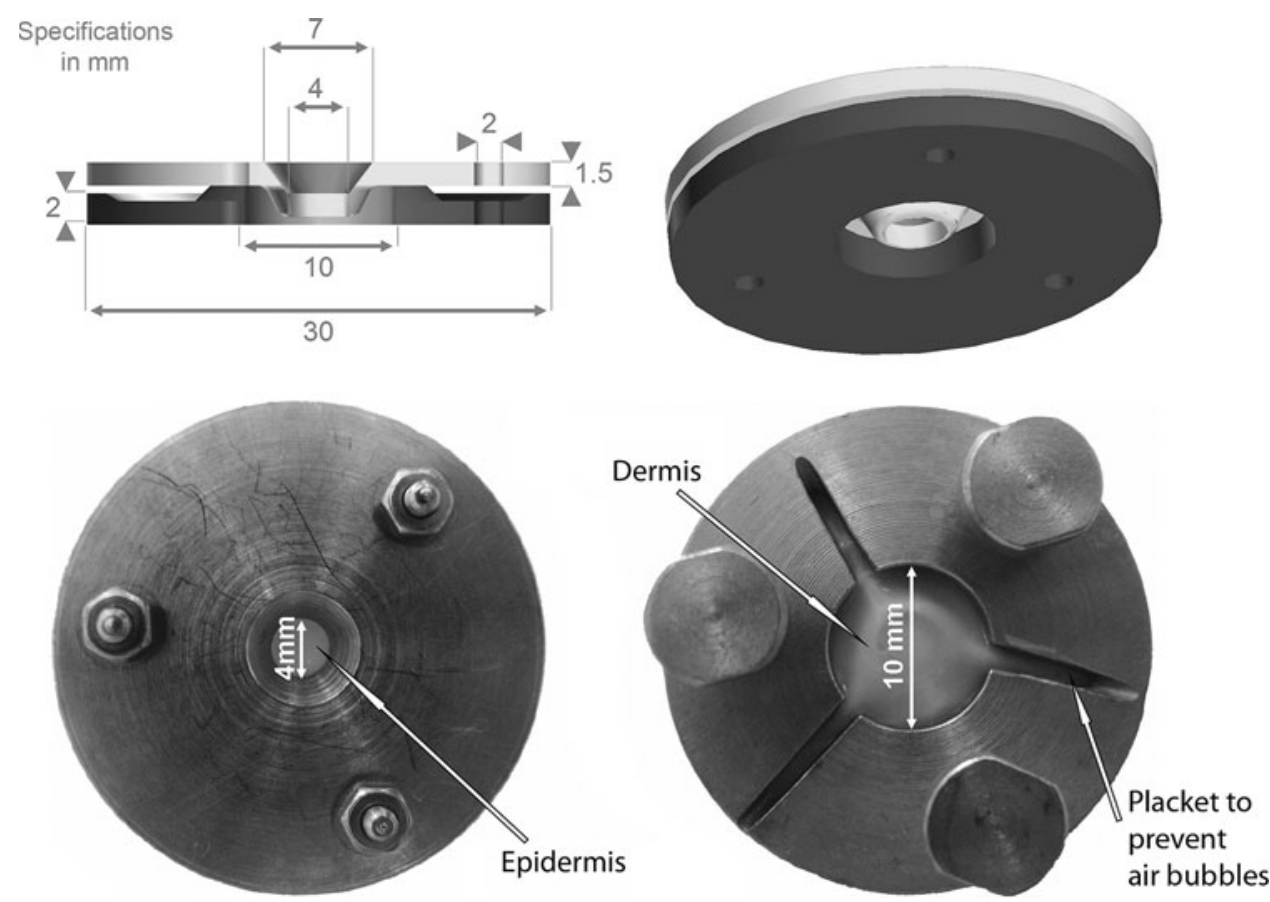

or S. aureus (ATCC 25923) by instilling the bacterial solution broadly into the inner opening.

\section{Assessment of wound infection}

For assessment of wound infection, tissue biopsies were harvested from the wound and homogenized in PBS (PT3100 Polytron, Kinematica, Littau-Luzern, Switzerland). Serially diluted aliquots of wound fluid and homogenate were analyzed on Luria-Bertani agar (International Diagnostics Group, Bury, Lancashire, UK) and Pseudomonas isolation agar (Becton Dickinson, Heidelberg, Germany) for counts of $S$. aureus and P. aeruginosa. After incubation for $18 \mathrm{~h}$ at $37^{\circ} \mathrm{C}, \mathrm{CFU}$ were counted, and CFU/g tissue was calculated as described previously [11].

\section{Immunohistochemistry}

Biopsy specimens were taken, fixed in $4 \%$ neutral buffered formalin, embedded in paraffin, and finally $4-\mu \mathrm{m}$ sections were prepared. For histological assessment, a standard H\&E staining of these sections was performed. After heat fixation, deparaffinization, antigen unmasking, and blocking, slides were incubated with the primary antibody [anti-S. aureus antibody (Acris, Herford, Germany) at a dilution of 1:1,000]. The slides were incubated overnight at $4^{\circ} \mathrm{C}$, rinsed with PBS several times, and incubated with a corresponding biotinylated secondary antibody for $30 \mathrm{~min}$ at room temperature (RT). After the washing procedure, sections were incubated in streptavidin Alexa Fluor488 conjugate for $30 \mathrm{~min}$ at RT.
The slides were rinsed again and DAPI counterstaining was performed. Finally, the slides were covered with fluorescent mounting medium (Dako, Hamburg, Germany). Pictures were taken using an Axioskop 2 plus microscope (Zeiss, Jena, Germany) connected to an AxioCam HRC camera (Zeiss, Jena, Germany) at 50- to 400-fold magnification.

\section{RNA isolation}

Skin tissue has been taken and weighed in order not to exceed $30 \mathrm{mg}$. Tissue was stored in liquid nitrogen until further processing. Isolation of total RNA was done using the RNeasy Mini Kit (Qiagen, Hilden, Germany), following the manufacturer's instructions for isolation of total RNA from heart, muscle and skin including DNAdigestion (RNase-free DNase Set, Qiagen, Hilden, Germany). RNA was eluted in a final volume of $30 \mu \mathrm{l}$ RNase-free $\mathrm{H}_{2} \mathrm{O}$. The concentration of RNA was determined using the Eppendorf Biophotometer (Eppendorf, Hamburg, Germany).

\section{Reverse transcription}

For reverse transcription, $1 \mu \mathrm{g}$ of total RNA was transcribed into cDNA using the SuperScript ${ }^{\mathrm{TM}}$ II First Strand Synthesis System for RT-PCR (Invitrogen, Karlsruhe, Germany), following the manufacturer's instructions for firststrand synthesis using random hexamer primers. cDNA was stored at $-20^{\circ} \mathrm{C}$. 


\section{Real-time PCR}

Relative quantification of mRNA was performed in a twostep real-time RT-PCR procedure using the fluorescent dye SYBR Green I (Light Cycler FastStart DNA Master SYBR Green I, Roche, Mannheim, Germany) and a Light Cycler 1.0 (Roche, Mannheim, Germany). The first step consisted of an RT reaction as described above, the second step of PCR amplification with specific primers listed in Table 1. These primer pairs were validated to generate a single PCR product. The PCR reactions were performed with $2 \mu \mathrm{l}$ of cDNA, $0.5 \mu \mathrm{M}$ of sense and antisense primers, $3 \mathrm{mM}$ $\mathrm{MgCl}_{2}$ and $2 \mu \mathrm{l}$ of FastStart SYBR Green reaction mix in a total volume of $20 \mu \mathrm{l}$. The cycling conditions were as follows: $95^{\circ} \mathrm{C}$ for $10 \mathrm{~min}$ at a ramp speed of $20^{\circ} \mathrm{C} / \mathrm{s}, 40$ cycles (if not differently described) consisting of $94^{\circ} \mathrm{C}$ for $15 \mathrm{~s}$ at a ramp speed of $20^{\circ} \mathrm{C} / \mathrm{s}$, A primer specific annealing temperature (Table 1) for $10 \mathrm{~s}$ at a ramp speed of $20^{\circ} \mathrm{C} / \mathrm{s}, 72^{\circ} \mathrm{C}$ for $10 \mathrm{~s}$ at a ramp speed of $20^{\circ} \mathrm{C} / \mathrm{s}$, followed by a melting point analysis: $95^{\circ} \mathrm{C}$ for $0 \mathrm{~s}$ at a ramp speed of $20^{\circ} \mathrm{C} / \mathrm{s}, 65^{\circ} \mathrm{C}$ for $15 \mathrm{~s}$ at a ramp speed of $20^{\circ} \mathrm{C} / \mathrm{s}, 95^{\circ} \mathrm{C}$ for $0 \mathrm{~s}$ at a ramp speed of $0.1^{\circ} \mathrm{C} / \mathrm{s}$, and finally a cooling phase: $40^{\circ} \mathrm{C}$ for $30 \mathrm{~s}$ at a ramp speed of $20^{\circ} \mathrm{C} / \mathrm{s}$. mRNA concentrations were corrected for $18 \mathrm{~S}$ rRNA in each sample and were normalized to an untreated control ( $x$-fold expression). Primer sequences for above-mentioned genes are as follows: $18 \mathrm{~S}$ sense $5^{\prime}$-gaaactgcgaatggctcattaaa-3'; $18 \mathrm{~S}$ antisense $5^{\prime}$-caca gttatccaagtaggagagg- $3^{\prime}$ [annealing temperature (AT) $60^{\circ} \mathrm{C}$; IFN- $\alpha$ sense $5^{\prime}$-acccacagcctggataacag- $3^{\prime} ;$ IFN- $\alpha$ antisense $5^{\prime}$-ctctcctcctgcatcacaca- $3^{\prime}$ (AT $60^{\circ} \mathrm{C}$ ); IFN- $\beta$ sense $5^{\prime}$-actgcctcaaggacaggatg- $3^{\prime}$; IFN- $\beta$ antisense $5^{\prime}$-agcc aggaggttctcaacaa $-3^{\prime}\left(\mathrm{AT} 60^{\circ} \mathrm{C}\right)$; IL- $1 \alpha$ sense $5^{\prime}$-aatgacgecc

Table 1 Primers for real-time PCR

\begin{tabular}{|c|c|c|}
\hline TG & Sequence $\left[5^{\prime} \rightarrow 3^{\prime}\right]$ & $\operatorname{AT}\left[{ }^{\circ} \mathrm{C}\right]$ \\
\hline IFN- $\alpha 1$ & $\begin{array}{l}\mathrm{f}: \text { acccacagcctggataacag } \\
r: \text { ctctcctcctgcatcacaca }\end{array}$ & 60 \\
\hline IFN- $\beta$ & $\begin{array}{l}\mathrm{f}: \text { actgcctcaaggacaggatg } \\
r: \text { agccaggaggttctcaacaa }\end{array}$ & 60 \\
\hline $\mathrm{IL}-1 \alpha$ & $\begin{array}{l}\mathrm{f}: \text { aatgacgccctcaatcaaag } \\
r: \text { tgggtatctcaggcatctcc }\end{array}$ & 60 \\
\hline IL-6 & $\begin{array}{l}\mathrm{f}: \text { caatgaggagacttgcctgg } \\
r: \text { gcacagctctggcttgttcc }\end{array}$ & 63 \\
\hline IL-8 & $\begin{array}{l}\mathrm{f}: \text { tctgcagctctgtgtgaagg } \\
r: \text { aatttctgtgttggcgcagt }\end{array}$ & 63 \\
\hline $\mathrm{TNF} \alpha$ & $\begin{array}{l}f: \text { aacctcctctctgccatcaa } \\
r: \text { ggaagacccctcccagatag }\end{array}$ & 62 \\
\hline $18 \mathrm{~S}$ & $\begin{array}{l}\mathrm{f}: \text { gaaactgcgaatggctcattaaa } \\
r: \text { cacagttatccaagtaggagagg }\end{array}$ & 60 \\
\hline
\end{tabular}

$T G$ target gene, $A T$ annealing temperature, $f$ forward primer, $r$ reverse primer tcaatcaaag- $3^{\prime}\left(\mathrm{AT} 60^{\circ} \mathrm{C}\right)$; IL- $1 \alpha$ antisense $5^{\prime}$-tgggtatctcaggc atctcc-3' (AT $60^{\circ} \mathrm{C}$ ); IL-6 sense $5^{\prime}$-caatgaggagacttgcctgg- $3^{\prime}$ (AT $63^{\circ} \mathrm{C}$ ); IL-6 antisense $5^{\prime}$-gcacagctctggcttgttcc- $3^{\prime}$ (AT $63^{\circ} \mathrm{C}$ ); IL-8 sense $5^{\prime}$-tctgcagctctgtgtgaagg- $3^{\prime}$ (AT $63^{\circ} \mathrm{C}$ ); IL-8 antisense $5^{\prime}$-aatttctgtgttggcgcagt- $3^{\prime}$ (AT $63^{\circ} \mathrm{C}$ ); TNF- $\alpha$ sense $5^{\prime}$-aacctcctctctgccatcaa-3' (AT $62^{\circ} \mathrm{C}$ ); TNF- $\alpha$ antisense $5^{\prime}$-ggaagacccctccagatag- $3^{\prime}\left(\right.$ AT $\left.62^{\circ} \mathrm{C}\right)$.

\section{Statistical analysis}

All assays were performed in triplicate. Data were analyzed using analysis of variance and independent samples $t$ test (SPSS, Chicago, IL). A $P$ value of less than 0.05 was considered significant compared to an untreated sample (control sample).

Acknowledgments This study was financially supported by the Deutsche Forschungsgemeinschaft (DFG). We sincerely thank Ms. Andrea Rittig for expert technical assistance.

Conflict of interest statement No potential conflicts of interest were disclosed.

Open Access This article is distributed under the terms of the Creative Commons Attribution Noncommercial License which permits any noncommercial use, distribution, and reproduction in any medium, provided the original author(s) and source are credited.

\section{References}

1. Calderon M, Lawrence WT, Banes AJ (1996) Increased proliferation in keloid fibroblasts wounded in vitro. J Surg Res 61:343347

2. Damour O, Augustin C, Black AF (1998) Applications of reconstructed skin models in pharmaco-toxicological trials. Med Biol Eng Comput 36:825-832

3. Davidson JM (1998) Animal models for wound repair. Arch Dermatol Res 290(Suppl):S1-S11

4. de Brugerolle A (2007) SkinEthic Laboratories, a company devoted to develop and produce in vitro alternative methods to animal use. ALTEX 24:167-171

5. Emanuelsson P, Kratz G (1997) Characterization of a new in vitro burn wound model. Burns 23:32-36

6. Gillery P, Bellon G, Coustry F et al (1989) Cultures of fibroblasts in fibrin lattices: models for the study of metabolic activities of the cells in physiological conditions. J Cell Physiol 140:483-490

7. Gottrup F, Agren MS, Karlsmark T (2000) Models for use in wound healing research: a survey focusing on in vitro and in vivo adult soft tissue. Wound Repair Regen 8:83-96

8. Greenwald DP, Gottlieb LJ, Mass DP et al (1992) Full-thickness skin wound explants in tissue culture: a mechanical evaluation of healing. Plast Reconstr Surg 90:289-294

9. Grinnell F (1994) Fibroblasts, myofibroblasts, and wound contraction. J Cell Biol 124:401-404

10. Hentzer B, Kobayasi T (1979) Adult human skin maintained in organ culture: I. The ultrastructure of the acellular compartment of connective tissue. Acta Derm Venereol 59:389-400

11. Jacobsen F, Baraniskin A, Mertens J et al (2005) Activity of histone H1.2 in infected burn wounds. J Antimicrob Chemother $55: 735-741$ 
12. Khetani SR, Bhatia SN (2006) Engineering tissues for in vitro applications. Curr Opin Biotechnol 17:524-531

13. Kirkpatrick CJ, Krump-Konvalinkova V, Unger RE et al (2002) Tissue response and biomaterial integration: the efficacy of in vitro methods. Biomol Eng 19:211-217

14. Krugluger W, Rohrbacher W, Laciak K et al (2005) Reorganization of hair follicles in human skin organ culture induced by cultured human follicle-derived cells. Exp Dermatol 14:580-585

15. Megyeri K, Mándi Y, Degré M et al (2002) Induction of cytokine production by different Staphylococcal strains. Cytokine 19:206212

16. Moll I (2003) Human skin organ culture. Methods Mol Med 78:305-310

17. Moll I, Houdek P, Schmidt H et al (1998) Characterization of epidermal wound healing in a human skin organ culture model: acceleration by transplanted keratinocytes. J Invest Dermatol 111:251-258

18. Paladini RD, Takahashi K, Bravo NS et al (1996) Onset of re-epithelialization after skin injury correlates with a reorganization of keratin filaments in wound edge keratinocytes: defining a potential role for keratin 16. J Cell Biol 132:381-397

19. Prunieras M, Regnier M, Woodley D (1983) Methods for cultivation of keratinocytes with an air-liquid interface. J Invest Dermatol 81:28s-33s

20. Puissant A (1976) Lyell's acute epidermal necrosis or bullous erythroderma with Debre-Lamy-Lamotte epidermolysis. Rev Stomatol Chir Maxillofac 77:735-739

21. Regnier M, Caron D, Reichert U et al (1993) Barrier function of human skin and human reconstructed epidermis. J Pharm Sci 82:404-407
22. Regnier M, Patwardhan A, Scheynius A et al (1998) Reconstructed human epidermis composed of keratinocytes, melanocytes and Langerhans cells. Med Biol Eng Comput 36:821-824

23. Robson MC, Mannari RJ, Smith PD et al (1999) Maintenance of wound bacterial balance. Am J Surg 178:399-402

24. Roupé KM, Nybo M, Sjöbring U et al (2009) Injury is a major inducer of epidermal innate immune responses during wound healing. J Invest Dermatol. doi:10.1038/jid.2009.284

25. Schindler M, Nur EKA, Ahmed I et al (2006) Living in three dimensions: 3D nanostructured environments for cell culture and regenerative medicine. Cell Biochem Biophys 45:215-227

26. Seiler WO, Stahelin HB, Zolliker R et al (1989) Impaired migration of epidermal cells from decubitus ulcers in cell cultures. A cause of protracted wound healing? Am J Clin Pathol 92:430-434

27. Steinstraesser L, Hirsch T, Beller J et al (2007) Transient non-viral cutaneous gene delivery in burn wounds. J Gene Med 9:949-955

28. Steinstraesser L, Rittig A, Gevers K et al (2009) A human full-skin culture system for interventional studies. Eplasty 9:e5

29. Tavakkol A, Varani J, Elder JT et al (1999) Maintenance of human skin in organ culture: role for insulin-like growth factor-1 receptor and epidermal growth factor receptor. Arch Dermatol Res 291:643-651

30. Website GENARS Project (2004) German Network for Antimicrobial Resistance. Available via http://www.genars.de. Accessed 30 September 2009

31. Website EARSS (2005) European antimicrobial resistance surveillance system. Available via http://www.rivm.nl/earss. Accessed 30 September 2009 